\title{
Teixeira de Freitas e a Autonomia das Partes no Direito Internacional Privado Latino-Americano
}

\author{
Dr. Jürgen Samtleben \\ Instituto Max Planck de Direito Privado \\ Estrangeiro e Internacional, Hamburgo *
}

A autonomia das partes é um dos temas mais famosos na história do direito internacional privado. Em que medida podem as partes derrogar as normas de conflito e definir elas mesmas o direito aplicável às suas relações mútuas? Este tema tem especial interesse para o direito internacional privado dos Estados latino-americanos onde até hoje dominam as tendências territorialistas ${ }^{(1)}$. É por isso que escolhemos esse tema para esta homenagem ao centenário do insigne jurista brasileiro Teixeira de Freitas. A nossa pesquisa tem por fim revelar as suas idéias sobre essa matéria e a sua projeção no direito latino-americano. Com isso queremos contribuir também para a aclaração e evolução do assunto no direito atual.

\section{Os antecessores}

Não se pode definir o lugar que Teixeira de Freitas ocupa na história do direito internacional privado latino-americano sem ter em conta a obra dos seus antecessores. Quando Freitas escreveu o seu Esboço, já uma geração antes dois famosos juristas do continente americano - Bello no sul e Story no norte - tinham publicado as suas obras que iriam influenciar profundamente o direito internacional privado latino-americano. Todavia, a obra de Freitas não mostra muitos pontos comuns com estes antecessores, antes toma nessa matéria como fundamento as idéias de Savigny e seu tratado de direito romano que tinha aparecido pouco antes na Alemanha. Vamos estudar a seguir o pensamento destes três internacionalistas para depois elucidar como em Freitas triunfa a influência européia sobre a tradição americana.

(*) Conferência pronunciada em Roma, 14 de dezembro de 1983, no Congresso Juridico Internacional comemorativo do centenário da morte de Augusto Teixeira de Freitas.

(1) J. SAMTLEBEN, Derecho Internacional Privado en América Latina (trad. C. BUENO-GUZMAN), I, Buenos Aires, 1983, 4 ss., 275 ss.; IDEM, El territorialismo de leyes en América Latina, in Primer Seminario Nacional de Derecho Internacional Privado. México, 1979, 171 ss. 


\section{Bello}

As idéias de Andrés Bello sobre o direito internacional privado se encontram assentadas no seu livro Principios de derecho de jentes, publicado no ano de 1832 em Santiago do Chile. Não quero expor aqui as razões que levaram Bello ao princípio da estrita territorialidade das leis, tema que tratei mais detalhadamente noutro lugar (2). Para Bello as leis de cada Estado regem todos os assuntos que se desenvolvem no seu território. Mas a sua obrigatoriedade se estende também aos atos realizados no estrangeiro, sempre que exista alguma conexão pessoal ou territorial com o próprio Estado.

Em matéria de contratos, Bello segue a teoria da incorporação. Um contrato deve ajustar-se em todos os seus aspectos à legislação do lugar da sua celebração, e as leis deste país supõem-se incorporadas no mesmo contrato. Porém, se o contrato tem que ser cumprido num outro Estado, este aplicará as suas leis respectivas (3). Em consonância com isso, o Código Civil chileno de 1855, magnífica obra pessoal de Bello, reconhece no seu artigo 16, segunda parte, o valor dos contratos validamente celebrados em pais estrangeiro. Mas os seus efeitos devem ajustar-se às leis chilenas, sempre que no Chile se encontre o lugar da sua execução.

Em nenhuma passagem da obra de Bello aparece a idéia de terem as partes a faculdade de escolher a lei aplicável ao contrato. É verdade que Bello escreve no seu livro que os tribunais têm que julgar sobre as obrigações recíprocas das partes «conforme as cláusulas expressas do contrato e as leis incorporadas nele» (4). E no seu Código Civil, artigo 1545, acolheu a norma do Code Napoléon segundo o qual o contrato é considerado como lei entre as partes ${ }^{(5)}$. Mas aqui trata-se somente da faculdade das partes definirem elas mesmas as condições materiais do contrato dentro dum sistema jurídico determinado ou da autonomia de direito privado. E mais tarde que se desenvolve dessa norma a idéia duma autonomia mais ampla que inclui a possibilidade da escolha da legislação competente pelas próprias partes.

\section{Story}

No ano de 1834, dois anos depois do livro de Bello, aparece nos Estados Unidos a obra de Joseph Story Commentaries on the Conflict of Laws, que na matéria de contratos mostra certa semelhança com as idéias do grande internacionalista chileno ${ }^{(6)}$. $\mathrm{Na}$ sua introdução histórica, Story começa com uma interpretação dos textos do Corpus

(2) J. SAMTLEBEN, La relación entre derecho internacional público y privado en Andrés Bello, in Revista Española de Derecho Internacional, 34, 1982, 399 ss.

(3) A. BELLO, Principios de derecho de jentes, Santiago, 1832, 44.

(4) Ibidem.

(5) V. art. 1134 C.c.francês.

(6) H. VALLADÄO, The Influence of Joseph Story on Latin-American Rules of Conflit of Laws, in American Journal of Comparative Law, 3, 1954, 27 ss 
Iuris (7). Cita a lex si fundus (D. $21,2,6$ ) que lhe parece subordinar os contratos à lei do lugar da celebragão. Por seu lado, a lei do lugar da execução do contrato encontraria apoio noutros textos do direito romano, especialmente na lex contraxisse (D. 44, 7, 21). Story comenta estes fragmentos e as várias tentativas dos juristas europeus de reconciliá-los numa interpretação moderna ${ }^{(8)}$.

Quantos às regras do common law, Story postula o império da lex loci contractus sobre os contratos, cuja validade, interpretação e resolução se regem pela lei do lugar da sua celebração. Esta regra funda-se, segundo Story, na necessidade do comércio entre as nações que já os romanos reconheceram no ius gentium ${ }^{(9)}$. Mas esta regra supõe que o contrato também deva ser executado no lugar da celebração ou que não tenha lugar específico para sua execução. Todavia. se o contrato se fez para ser executado num outro país, aplicam-se as leis desse lugar, em conformidade com os textos romanos citados (10)

Qual é o papel da vontade das partes nessa matéria de contratos que Story vê dominada pela lei do lugar da celebragão ou da execução do contrato? O próprio Story parece admitir que a razão tanto da lex loci celebrationis como da lex loci executionis se encontra no consenso tácito ou implícito das partes (11). Contudo. deixa bem claro que não se trata duma verdadeira submissão a essa lei, mas antes dum efeito da soberania territorial que se impõe ao contrato independentemente de toda vontade das partes ${ }^{(12)}$. Assim fica excluída por completo a noção da autonomia da vontade ou da eleição da lei aplicável que só no meio do século reaparece na doutrina européia.

\section{Savigny}

Em 1849 apareceu na Alemanha o oitavo tomo do Sistema do direito romano atual de Carl Friedrich von Savigny. Este tomo, que se ocupa com os limites no espaço e tempo do império das regras de direito sobre as relações jurídicas, significou uma revolução coperniciana para o direito internacional privado europeu ${ }^{(13)}$. Vamos expor a seguir os pontos essenciais da sua teoria e especialmente a sua doutrina na matéria dos contratos.

(7) J. STORY, Commentaries on the Conflict of Laws, Boston, 1834, § 233.

(8) Op. cit., § 234 ss.

(9) Op. cit., \& 241 ss.

(10) o. cit., $\$ 280$.

(11) Op. cit., $\S \S 261,280$.

(12) Op. cit., § 261: «It would be more correct to say, that the law of the place of the contract acts upon it, independently of any volition of the parties, in virtue of the general sovereignty possessed by every nation to regulate all persons, property, and transactions within its own territory.»

(13) P.H NEUHAUS, Die Grundbegriffe des Internationalen Privatrechts 2, Tübingen, 1976,94 


\section{a) O lugar da relação jurídica}

No seu livro Savigny parte de uma visão histórica do assunto (14). Faz relembrar como os direitos germânicos se sobrepunham ao direito romano, estabelecendo-se o sistema da vigência pessoal dos respectivos direitos. Mais tarde, no tempo medieval, ganhavam importância os estatutos particulares das cidades italianas, surgindo o problema da delimitação territorial destes estatutos. Aqui nasceu a teoria dos statuta personalia, realia, mixta, que pretendia definir com esta divisão o âmbito da aplicação das respectivas leis.

Também para Savigny, no tempo moderno, esta delimitação territorial das legislações forma o núcleo do problema. A sua fórmula, porém, com a qual tenta descrever esse problema, é nova e auspiciosa. Em vez de definir o âmbito de aplicação para as diferentes classes de leis, Savigny procura para cada relação jurídica o «lugar» ao qual pertence. Assim indica como finalidade do direito internacional privado

«determinar para cada relação jurídica o lugar de direito ao qual esta relação jurídica conforme a sua natureza própria pertence ou está submetida»(15).

Este lugar se refere igualmente aos territórios dos diferentes Estados como dentro de cada Estado às divisões territoriais que têm um direito particular. Noutra parte do seu livro, Savigny identifica este lugar de direito (Rechtsgebiet) com a «sede» (Sitz) da relação jurídica ${ }^{(16)}$. É esta expressão que depois teve grande repercussão na evolução do direito internacional privado europeu.

\section{b) A lei da obrigação contratual}

Qual é o «lugar» do contrato nessa concepção ideal de Savigny? Procurando o lugar da obrigação, Savigny identifica-o com o foro competente para decidir dela. Pergunta então: «Onde está a sede da obrigação? Onde está o foro especial dela? Onde encontramos a lei territorial que lhe é aplicável? A primeira destas três questões é de natureza teórica e serve unicamente de base à solução das outras; por isso deve ser tratado junto com a segunda ${ }^{(17)}$.» Savigny vê claramente que este método leva à divisão do contrato, que muitas vezes contém duas obrigações recíprocas, e que tal divisão pode, especialmente quanto ao direito aplicável, «suscitar dúvidas e acarretar complicações». Mas nem por isso o princípio deixaria de ser certo ${ }^{(18)}$.

(14) C.F. v. SAVIGNY, System des eutigen römischen Rechts, VIII, Berlin, 1849, 19 ss.

(15) Op. cit., 28.

(16) Opt. eit., 108.

(17) Op, cit., 205 s.

(18) Op. cit., 202 (b). 
Neste sentido, o «lugar» do contrato não coincide necessariamente com o lugar da sua celebração. Antes é preciso definir para cada obrigação o seu foro especial que está no lugar da sua execução. Para isso Savigny se baseia nas fontes do direito romano ${ }^{(19)}$, especialmente na lex 21 de obl. et act. (D. 44, 7): «Contraxisse unusquisque in eo loco intellegitur, in quo ut solveret se obligavit.» Mas como definir este lugar, se as partes não estipularam nada sobre isso, e se este lugar não resulta claramente da natureza da obrigação? Neste caso, segundo Savigny, o lugar da execução define-se subsidiariamente: pelo centro da atividade do devedor ou pelo seu domicílio se nele se celebrou o contrato, pelo lugar da celebração do contrato fora do domicilio do devedor se pelas circunstâncias neste lugar deveria ser cumprido, e ultimamente pelo domicílio atual do devedor (20). Por estes mesmos lugares determina-se o direito aplicável a cada obrigagão ${ }^{(21)}$.

\section{c) A vontade das partes}

Mas a questão principal da presente investigação é a seguinte: Podem as partes livremente escolher o direito aplicável ao contrato e definir assim o «lugar» da obrigação? Aqui o texto de Savigny é suscetivel de diferentes interpretações. Diz ele textualmente: «O direito territorial aplicável a cada relação jurídica está fortemente influenciado pela livre vontade das pessoas interessadas ou pela submissão voluntária a um lugar determinado de direito, embora esta influência não seja ilimitada. A mesma submissão voluntária também tem a sua importância quanto ao foro competente para as diversas relações jurídicas. A submissão voluntária a um direito territorial aparece em diferentes formas e graus. Às vezes escolhe-se livremente o conteúdo de um direito territorial determinado em vez de outro conteúdo possivel; assim acontece especialmente nos contratos do direito das obrigações, podendo considerar-se o direito territorial livremente escolhido quase uma parte integrante do próprio contrato ${ }^{(22)}$.»

Uma parte da doutrina considera que essa submissão voluntária na concepção de Savigny se refere unicamente à escolha do lugar de execução (23). Conforme esta interpretação, as partes podem livremente eleger o lugar da execução se a isso não se opõe a natureza do contrato. Porém, uma vez determinado o lugar da execução e

(19) Op. cit., 208 ss., 251 ss.

(20) Op. cit., 211 ss., 226 s.

(21) Op. cit., 203, 246 ss.

(22) Op. cit., 110.

(23) K. NEUMANN, Vertragsgültigkeit und Parteiwille in Lehre und Rechtsprechung des internationalen Schuldrechts, Heidelberg, 1930, 29 ss.; R. MOSER, Vertragsabschluss, Vertragsgültigkeit und Parteiwille im internationalen obligationenrecht, St. Gallen, 1948, 142 s.; A. WICKI, Zur Dogmengeschichte der Parteiautonomie im Internationalen Privatrecht, Winterthur, 1965, $32 \mathrm{~s}$. 
com isso a legislação territorial aplicável, as partes já não se podem afastar do conteúdo dela a não ser na medida em que seja permitido pela mesma legislação. Esta interpretação que somente concede às partes a faculdade de eleger indiretamente a legislação aplicável e reconhece apenas a autonomia de direito privado no âmbito dessa legislação, também se reflete na evolução posterior do direito internacional privado latino-americano ${ }^{(21)}$.

Mas alguns trechos da obra de Savigny justificam a impressão de que ele já teve a visão de uma autonomia ${ }^{(25)}$ mais ampla que engloba também a faculdade das partes de eleger diretamente o direito territorial aplicável como «parte integrante do próprio contrato», seja ela ou não a lei do lugar da execução do contrato. Assim diz sobre o foro do contrato: «É sempre o lugar da execução que determina o foro especial, seja fixado por declaração expressa ou por aceitação tácita. Em ambos os casos trata-se duma submissão voluntâria a este foro, a não ser que seja excluído por declaração expressa em sentido contrário ${ }^{(26)}$.» E igualmente sobre o direito aplicável, depois de enumerar as diversas maneiras de determinar o lugar da execução pela vontade expressa ou implícita das partes, conclui: «Este direito territorial deixa também de ser aplicável, se à presunção da submissão voluntária se opõe uma declaração expressa em sentido contrário ${ }^{(27)}$.» Para isto baseia-se ainda num texto do direito romano (D. $5,1,19 \S 2)$ : «nisi alio loci, ut defenderet, convenit.. » $\hat{E}$ verdade que Savigny admite esta eleição do direito aplicável somente «na medida em que as disposições do direito territorial podem ser modificadas pelas partes» (28). Mas parece que aqui se refere às normas absolutas que pouco antes menciona como limites de qualquer submissão voluntária e que correspondem hoje em dia às leis de ordem pública internacional.

É essa visão da autonomia das partes na eleição do direito aplicável que prosperou depois na doutrina européia e domina o direito internacional privado moderno. Segundo esta concepção, as partes podem livremente escolher a lei do contrato e assim derrogar não só as normas dispositivas mas também as disposições obrigatórias da lei normalmente aplicável, sendo o único limite a ordem pública da lex fori. Vamos ver em seguida como a obra de Savigny influenciou profundamente o pensamento de Teixeira de Freitas e determinou sua posição no assunto.

(24) V. infra III.

(25) As críticas de v. SAVIGNY, op. eit., (supra n. 14), 112 s., contra esta expressão, que ele queria reservar para os privilégios da nobreza, são somente de caráter terminológico.

(26) Op. cit., 227 s.

(27) Op. eit., 248 s.

(28) Op. cit., 249 (c). Nessa nota baseia-se a opinião que Savigny admitia só a autonomia de direito privado no âmbito do direito dispositivo, NEUMANN, op. cit. (supra $n \mid$ 23), 30; este autor, ibidem 31 s., destrói o seu próprio argumento citando um exemplo de Savigny. 


\section{A obra de Teixeira de Freitas}

Para o pensamento de Teixeira de Freitas referimo-nos em primeiro lugar a seu Esboço de Código civil, publicado entre 1860 e 1865. $\mathrm{E}$ verdade que não se pode imaginar esta obra sem o seu antecessor, a Consolidação das leis civis aparecido pouco antes em $1857^{(29)}$. Mas para conhecer as idéias próprias de Teixeira de Freitas e para avaliar a sua originalidade é preciso partir do Esboço que contém o cúmulo do seu pensamento jurídico. Somente nesse quadro da nossa exposição recorremos também à Consolidação para sublinhar a evolução da doutrina de Freitas no campo do direito internacional privado.

\section{O lugar dos objetos jurídicos}

A influência de Savigny em Teixeira de Freitas já se mostra claramente no Título preliminar do Esboço, Capítulo I: «O lugar». Aqui encontramos todas as idéias nas quais Savigny fundamentou a sua teoria de direito internacional privado. $\mathrm{Na}$ nota a este capítulo, também Freitas rejeita a teoria dos estatutos: «A velha distincção entre statutos pessoaes, statutos reaes, e statutos mixtos, craveira artificial, em vão manejada por tantos Escriptores, para dirimir questões de conflicto de leis privadas, não tem a menor importância, só tem valor historico.» Em vez desta distinção é preciso «determinar a sede» de cada um dos objetos jurídicos que são as pessoas, coisas, fatos e direitos, ou o «lugar» deles ${ }^{(30)}$.

Sobre este «lugar», o Esboço de Freitas contém nos artigos 3 e 4 as regras seguintes:

Art. 3: «Distinguir-se-ha o l ugar, para os os effeitos declarados neste Codigo, pelos territorios diversos de cada paiz em relação ao território do Imperio; e, dentro do Imperio, pelas divisões territoriaes de sua organisação judiciaria.»

Art. 4: «Os effeitos do 1 u g a r são:

$1^{0}$ - Determinar a legislação civil applicavel, ou deste Codigo, ou de paiz estrangeiro.

$2^{\circ}$ - Determinar em geral a jurisdição das autoridades judiciais do Imperio.

$3^{\circ}$ - Determinar a competncia das autoridades judiciaes do Imperio entre si.»

(29) Sobre a relação entre consolidação e codificação do direito v. S. SCHIPANI, Dal diritto romano alle codificazione latino-americane: l'opera di $A$. Teixeira de Freitas, in Studi Sassaresi, III, v. 5, 1977-78 (1981), 589 sS., 598.

(30) A.T. DE Freitas, Código civil, Esbogo, Rio de Janeiro, 1860, 1 ss., 4. 
Aqui aparece o mesmo significado do lugar tanto em relação aos territórios dos diferentes Estados como em relação às divisões territoriais dentro dum Estado. E se destaca como efeito do lugar a determinação da lei aplicável e igualmente do foro competente. Comparado com as idéias de Savigny, a semelhança é evidente.

\section{A lei do contrato}

Na matéria dos contratos, Teixeira de Freitas partiu das normas do velho direito português e do direito imperial, que recolheu na Consolidação. No Esboço, então, mostra-se claramente a influência das idéias de Savigny, que sofrem porém uma modificação importante. Vê-se nessa evolução a madureza e a originalidade do pensamento de Freitas.

\section{a) Os contratos na Consolidação}

A legislação portuguesa aplicável no Brasil continha nas Ordenações para os contratos o princípio do locus regit actum (Ord. $3,59,1$ ). No Império, o regulamento $\mathrm{n}^{\circ} 737$ de 1850 sobre o processo comercial acrescentou algumas regras, explicando e generalizando as normas dispersas do Código comercial de 1850. Para os contratos ajustados em país estrangeiro o art. $3 \S 2$ reproduz a regra locus regit actum, excetuando-se os contratos celebrados ante um cônsul brasileiro. Porém, os contratos comerciais, ajustados em país estrangeiro mas exequíveis no Império, regulam-se pela legislação comercial do Brasil (art. 4). Igualmente, as dívidas contraídas entre brasileiros em país estrangeiro presumem-se sujeitas à legislação brasileira (art. 5). Não é difícil notar a semelhança destas regras, que significam nos casos mencionados uma exceção unilateral em favor do direito brasileiro, com as idéias de Andrés Bello antes expostas (31).

Freitas incluiu estas regras na sua Consolidação, arts. 406-410, mas no seu comentário estendeu a sua vigência no sentido bilateral. Assim, a regra locus regit actum que tem aplicação aos contratos ajustados em país estrangeiro encontra-se no art. 406, com a ressalva no art. 407 para os contratos celebrados ante cônsules brasileiros. Igualmente, a aplicação da lei brasileira aos contratos exequíveis no Brasil, ou contraídos entre brasileiros, é confirmada nos arts. 409 e 410. Porém, Freitas interpreta estas normas no sentido que tanto a regra locus regit actum como a exceção para os contratos entre brasileiros somente se referem à celebração do contrato. Por seu lado, os efeitos dos contratos regulam-se em qualquer caso pela lei do lugar da execução, seja este no Brasil ou em país estrangeiro ${ }^{(32)}$. Não há dúvida que se mostra aqui a influência direta das idéias de Savigny.

(31) Supra I 1.

(32) A.T. DE F..REITAS, Consolidação das leis civis 3, Rio de Janeiro, 1896, 283 s. notas $101 \mathrm{~s}$. 


\section{b) Os contratos no Esboco}

Estas idéias se refletem mais claramente nas regras do Esboço sobre os contratos. Para a forma dos contratos encontramos também aqui a regra locus regit actum (arts. 1935 s.), com certas aclarações a respeito do lugar da celebração no caso de uma forma especial ou dum contrato entre ausentes, que lembram com algumas modificações as idéias de Savigny sobre este ponto ${ }^{(33)}$. Porém, para os efeitos dos contratos que rege é a lei do lugar de cumprimento, ficando este no Império ou em país estrangeiro (art. 1962). E, para definir este lugar do cumprimento, Freitas segue quase literalmente os critérios de conexão que já Savigny enumerava: o lugar designado para o cumprimento do contrato ou que resulte da natureza da obrigação, o domicílio do devedor se nele se celebrou o contrato, o lugar da celebração do contrato fora do domicílio do devedor se pelas circunstâncias neste lugar deveria ser cumprido, e subsidiariamente o domicílio atual do devedor (art. 1963).

Todavia, enquanto Savigny tratava somente do lugar da execução para cada obrigação particular, Freitas em princípio tenta definir o lugar do cumprimento do próprio contrato, evitando assim as «dúvidas e complicações» que resultam da aplicação de diferentes leis às obrigações recíprocas ${ }^{\left({ }^{34}\right)}$. Assim supõe implicitamente que o lugar de cumprimento designado pelas partes ou resultante das circunstâncias é o centro das obrigações contratuais, justificando a aplicação da respectiva legislação ao contrato inteiro. Com isso corresponde a regra do art. 1963 n 5 do Esboço, conforme a qual no caso de vários lugares de cumprimento designados ou em caso de dúvida sobre o lugar de celebração ou o domicílio do devedor, é decisivo o lugar «cujas leis forem mais favoráveis à plenitude da intenção das partes contratantes». Somente os contratos celebrados entre ausentes, e «não havendo lugar designado para seu cumprimento», se regem em relação a cada uma das partes pelas leis de seu domicílio (art. 1964), mantendo-se neste caso o sistema de divisão do contrato.

Contudo, as regras do Esboço sobre os contratos expressam uma idéia bem moderna que nessa forma não se encontra na obra de Savigny. Enquanto este procura em primeiro lugar o foro especial e a respectiva lei territorial para cada obrigação contratual, Freitas vê claramente que o decisivo é a lei do contrato. É esta idéia que o leva conseqüentemente a reconhecer a autonomia das partes na determinação dessa lei.

\section{A autonomia das partes}

Determinar a lei do contrato resulta difícil quando este tem contatos com vários países, isto é, nos contratos internacionais. Eis

(33) Cr. C.F. v. SAVIGNY, Op. cit. (supra n. 14), 234 ss., 256 ss., 348 ss., 354

(34) V. supra I 3 b), 
aqui a razão porque as partes na prática incluem cláusulas nos mesmos contratos que designam não só o foro do contrato mas também a lei que será aplicável às relações contratuais. Teixeira de Freitas reconhece esta prática na sua obra, dando assim pleno valor à autonomia das partes nesta área do direito internacional privado.

\section{a) $\mathbf{O}$ domicílio eleito}

Já na Consolidação, art. 393, Freitas mencionou as cláusulas da eleição do foro, baseando-se nas regras das Ordenações e do regulamento $\mathrm{n}^{\circ} 737$ sobre processo comercial ${ }^{(35)}$. No seu comentário deixa bem claro que este foro eleito não coincide com o lugar da execução, mas resulta da faculdade das partes fixarem autonomamente o foro do contrato. «Ha fôro do contracto, ou a parte assim estipule, ou se obrigue a pagar em certo logar. O logar do pagamento é o logar em que o crédor póde demandal-o, a não haver estipulação expressa em contrario ${ }^{(36)}$.» No Esboço encontramos este foro do contrato no art. 1968, exigindo forma escrita para esta cláusula e restringindo o seu âmbito à eleição do foro dentro do Império.

Mas desse foro do contrato desenvolve-se no Esboço outra idéia que é o domicílio eleito. O domicílio para Freitas determina o «lugar» das pessoas no sentido em que ele usa esta expressão no art. 4 do Esboço ${ }^{(37)}$. Assim a definição do domicílio no art. 30 do Esboço abrange tanto a noção da legislação aplicável às pessoas a respeito da sua capacidade «e mais casos que fôrem neste Código designados», como a competência das autoridades judiciais do Império entre si. Da eleição desse domicílio pelas partes trata o art. 32:

«O domicílio especial será o que as partes elegêrem por contracto em relação á certo e determinado negocio, para um ou outro dos effeitos do Art. 30, nos casos, e pela fôrma, que se determinar na legislação deste Código sobre contractos.»

No seu comentário Freitas explica que isso é o que se costuma chamar «domicílio eleito» ou «foro do contrato». E continua: «O nosso art. contém uma outra ideia, além da do domicílio eleito para fôro do contracto; indicando também o domicilio eleito para o fim de se applicar ao caso uma legislação determinada. A conservação do domicílio, com os dous effeitos do Art. 30, é voluntaria, pois que não se deve tolher a liberdade das partes, sempre que o exercicio della não fôr incompativel com a ordem publica. O que se quer é a certeza de um lugar, como indicador da legislação applicavel; e esta certeza existe, quando as partes convencionão que o seu contracto será regido e julgado pelas leis de um paiz determinado ${ }^{(38)} . »$

(35) Ord. 3,6,2 e 3.11,1: Regulamento no 737, arts. 62 e 64 .

(36) A.T. DE FREITAS, Consolidação cit. (supra ne 32), 274 nota 85.

(37) V. supra II 1.

(38) A.T. DE FREITAS, Esbogo cit (supra a 30), 39, 
Aqui aparece claramente a idéia da autonomia das partes que têm plena faculdade de escolher a lei do contrato. O comentário de Freitas não deixa dúvida de que as partes podem livremente escolher o «lugar» do contrato sujeitando-o à legislação dum país determinado. Esta liberdade encontra seu único limite na ordem pública.

\section{b) O enigma do art. 1965}

$\mathrm{O}$ art. 32 do Esboço remete-nos, para as particularidades do domicílio eleito, à regulação «que se determinar na legislação deste Codigo sobre contractos». E no capítulo sobre os contratos encontramos no art. 1965 a disposição correspondente ao assunto. Diz esta norma com certa ênfase:

«Não prevalece o disposto nos arts. 1936 e 1937:

$1^{\text {? }}$ - Quando as partes nos respectivos instrumentos ou em instrumento posterior, houverem convencionado que o contracto seja julgado pelas leis do Imperio ou pelas de um paiz estrangeiro determinado (art. 32).

$2^{\circ}$ - Quando as partes nos respectivos instrumentos, ou em instrumento posterior, se tiverem obrigado a responder pelo contracto no Imperio, ou num paiz estrangeiro determinado (art. 32).»

Esta disposição refere-se diretamente à norma do art. 32, reconhecendo tanto a eleição da lei do contrato como a escolha do foro do contrato no âmbito internacional. $\dot{\mathrm{E}}$ verdade que o art. 32 estabelece o domicílio eleito somente com os efeitos do art. 30, isto é, quanto à legislação aplicável e à competência territorial dentro do Império. Por seu lado, o art. 1965 estende esta faculdade das partes também à eleição do foro competente no nível internacional.

Todavia, o que suscita dúvidas sobre o verdadeiro alcance do art. 1965, é a primeira parte do preceito que se refere aos arts. 1936 e 1937. O art. 1936 trata da lei aplicável à forma dos contratos entre ausentes, e o art. 1937 contém uma regra de direito substantivo sobre a prova dos contratos. Agora, o texto do art. 1965 exclui meramente a aplicação destes dois artigos, no caso das partes elegerem, ou no contrato ou por um acordo posterior, a lei do contrato ou o foro contratual. Parece assim que a referência aos arts. 1936 s. restringe o efeito desta eleição a pormenores sem maior importância.

Porém, esta interpretação literal do art. 1965 levanta uma série de questões cuja solução parece enigmática. Como se combina este efeito restringido do art. 1965 com a ampla noção do domicílio eleito no art. 32 e a interpretação de Freitas sobre esta disposição? Se o alcance do art. 1965 atinge somente a forma e a prova dos contratos, por que não figura esta norma nas respectivas secçóes do Esboço, mas na secção que trata dos efeitos dos contratos? '.E se o conteúdo 
do art. 1965 se refere claramente à questão da legislação aplicável ou ao direito internacional privado, que sentido pode ter a referência a uma norma de direito substantivo? O texto do art. 1965 deixa-nos sem solução, e para esta parte do Esboço não existe comentário de Freitas que nos poderia elucidar o assunto.

\section{c) A solucão}

A seguir vamos apresentar uma solução do problema que pode parecer um pouco ousada ou talvez demasiado simples, conforme o ponto de vista, e que certamente contém um elemento de especulação. Para isso partimos da suposição que o texto citado do art. 1965 é o original como se encontra no vol. 3 do Esboço publicado em 1865. Não nos foi possível examinar esta edição da obra, mas todas as publicações ulteriores que tivemos à disposição reproduzem este texto na mesma forma ${ }^{(39)}$, o que nos permite excluir a possibilidade duma alteração posterior do texto. O que pensamos, porém, é que o texto do art. 1965 já foi alterado na edição de 1865 e que não correspondeu à verdadeira intenção de Freitas.

Isso é fácil imaginar quando nos lembramos das circunstâncias em que Freitas terminou o seu trabalho no Esboço ${ }^{(40)}$. Já pelo aspecto exterior se nota certa diferença entre as primeiras partes do Esboço com seu comentário detalhado e as partes ulteriores que se limitam à simples reprodução dos textos de disposições. A última parte do Esboço nem chegou a ser publicada. Estes fatos já mostram claramente as dificuldades que Freitas tinha que vencer para prosseguir com a publicação da obra. Não será provável que neste esforço podia ocorrer facilmente um erro de imprensa sem ser notado? E não sabemos todos que um autor mesmo com o maior cuidado não pode evitar tais erros?

Somos por isso da opinião que a primeira parte do art. 1965 deve dizer assim: «Não prevalece o disposto nos arts. 1963 e $1964 \ldots$... . O primeiro destes dois artigos contém a enumeração dos critérios de conexão para definir o lugar de cumprimento, e o segundo trata da divisão do contrato celebrado entre ausentes. Para evitar as dificuldades que podia levar a definição do lugar de cumprimento do contrato ou a divisão das obrigações recíprocas, Freitas queria abrir no art. 1965 a possibilidade das partes definirem num acordo comum a lei do contrato. Talvez tenha escrito: «Não prevalece o disposto nos arts. 1963 s. . . », o que por erro tipográfico se converteu em «arts. 1936 s.», depois corrigido em «arts. 1936 e 1937». Assim se explicaria o texto publicado do art. 1965.

(39) A.T. DE FREITAS, Código civil: obra fundamental del Código civil argentino (trad, castellana), I, Buenos Aires, 1909, 657 s.; H. VALLAADÃO, O direito internacional privado no Esboco de Teixeira de Freitas, in Revista Jurídica da Faculdade Nacional de Direito da Universidade do Brasil, 8, 1944-1945, 335 ss., 385 s.; IDEM, Material de classe de direito internacional privado 11, Rio de Janeiro, 1980, $254 \mathrm{~s}$.

(40) Cf. S. MEIRA, Teixeira de Freitas: o jurisconsulto do Império, Rio de Janeiro, $1979,218,228$ ss., 368 ss. 
Não sabemos se a nossa hipótese é convincente para todos. Seja como for, da leitura das passagens de Freitas antes citadas, pode-se deduzir claramente que ele já reconheceu a autonomia das partes na forma mais ampla sem fixar para ela outro limite que a ordem pública. Com isso Teixeira de Freitas alinha-se entre os precursores da teoria moderna da autonomia de vontade que só neste século chegou a dominar na teoria do direito internacional privado. Optando entre esta visão de Freitas que aparece inequivocamente na sua obra e o texto dum artigo evidentemente mutilado inclinamo-nos sem hesitar pela visão do gênio e contra o texto literal.

\section{A projeção de Freitas no direito internacional privado latino- -americano}

O princípio da autonomia da vontade das partes para definir a lei aplicável ao contrato é hoje em dia amplamente reconhecido no direito internacional privado europeu. Outra foi a evolução do assunto no âmbito latino-americano onde as tendências territorialistas nunca admitiram uma influência real das partes na escolha do direito aplicável. Assim as idéias de Freitas, prematuras e visionárias no seu tempo, perderam-se na corrente poderosa do territorialismo que parece corresponder às exigências político-sociais do subcontinente.

\section{Brasil}

No Brasil, as idéias de Freitas nuncd chegaram a converter-se em lei. O Código Civil de 1916, na sua Introdução, mantinha a tradição do direito antigo a respeito dos contratos internacionais, deixando pouco lugar à autonomia das partes. A nova Lei de Introdução de 1942, mais rígida no assunto, parece descartar esta possibilidade por completo.

\section{a) A Introdução de 1916}

O autor do Código Civil de 1916, Clóvis Beviláqua, ainda foi mais liberal no seu projeto. Baseando-se no art. 4 do Código Comercial português de 1888, queria regular os contratos em sua substância e efeitos pela lei do lugar da celebração, admitindo expressamente uma estipulação em contrário. e a sua execução pela lei do lugar do cumprimento ${ }^{(41)}$. Esta concepção, porém, foi modificada no processo parlamentário. Dizia o art. 13 Intr. na sua redação final:

«Regulará, salvo estipulação em contrário, quanto à substância e aos efeitos das obrigações, a lei do lugar onde foram contraídas.

(41) V. art. 3b do projeto Clóvis Beviláqua, reproduzldo pư J.L. ALVES, Código civil da República dos Estados Unidos do Brasil anotado, Rio de Janeiro, 1926, 18. 
$\S$ único. Mas sempre se regerão pela lei brasileira:

I - Os contratos ajustados em países estrangeiros, quando exequíveis no Brasil.

II - As obrigações contraídas entre brasileiros em país estrangeiro.

III - Os atos relativos a imóveis situados no Brasil.

IV - Os atos relativos ao regime hipotecário brasileiro.»

Este texto estava inspirado pelas regras do direito brasileiro antigo que também Freitas tinha acolhido na sua Consolidação; mas a lei não aceitou a sua interpretação bilateral. Ao contrário, a ressalva em favor do direito brasileiro aqui ficou ainda mais estendida. A jurisprudência baseou-se nesta disposição para aplicar quase sempre o direito brasileiro aos contratos internacionais ${ }^{(42)}$.

Contudo, o art. 13 previa, em princípio, também uma estipulação das partes sobre o direito aplicável. Porém, esta possibilidade foi interpretada pela doutrina brasileira no sentido de se referir somente ao direito dispositivo ${ }^{(43)}$. E o art. 13 excluía tal eleiçáo da lei aplicável quando se tratava de contratos exequíveis no Brasil. Assim, o Supremo Tribunal Federal num caso, em que as partes convencionaram a aplicação do direito da Luisiania ao seu contrato, sentenciou «que tal clausula, sendo offensiva do direito nacional, reputa-se não escripta e inexistente» ${ }^{(44)}$. Com isso, a autonomia das partes neste âmbito ficou terminantemente proibida.

\section{b) A Lei de Introdução de 1942}

Adveio a nova Lei de Introdução de 1942 que trouxe para as obrigações no seu art. 9 a seguinte regra:

«Para qualificar e reger as obrigações, aplicar-se-á a lei do país em que se constituírem.

$\S 1^{\circ}$ - Destinando-se a obrigação a ser executada no Brasil e dependendo de forma especial, será esta observada, admitidas as peculiaridades da lei estrangeira quanto aos requisitos extrínsecos do ato.

$\S^{0} 2$ - A obrigação resultante do contrato reputa-se constituída no lugar em que residir o proponente.»

(42) V. jurisprudência citada por P.G. GARLAND, American-Brazilian Private International Law, New York, 1959, 52 s.

(43) V. doutrina citada por H. VALLADÃO, Direito internacional privado 5, I, Rio de Janeiro - São Paulo, 1980, 366; I. STRENGER, Da autonomia da vontade em direito internacional privado, São Paulo, 1967, 194 ss.

(44) Supremo Tribunal Federal, Ac. 13.12-1924, Agravo de petição n̊ 3927, «Estado do Ceará c. Bayley \& Cia.», Revista do Supremo Tribunal Federal, 91, 1925, 45 ss., 50. 
Reaparece aqui a velha regra da lex loci contractus, modificada em certa forma em favor da lei brasileira quando esta é a lex loci executionis. Não queremos entrar em detalhes sobre a origem e a interpretação desta disposição ${ }^{(45)}$. Parece certo que o texto queria intencionalmente excluir a determinação da lei do contrato pelas partes. A doutrina está dividida no assunto, não admitindo a eleição da lei aplicável ou somente na medida em que tal eleição seja permitida pela lei competente ${ }^{(46)}$. Também se indica a possibilidade duma eleição indireta da lei do contrato pela determinação do lugar da celebração, valendo-se da regra do art. $9 \S 2$ da Lei de Introdução ${ }^{(47)}$. A jurisprudência dos tribunais segue na sua tendência tradicional de aplicar o direito brasileiro aos contratos internacionais sem admitir uma eleição do direito estrangeiro ${ }^{(48)}$. E o Supremo Tribunal Federal, numa decisão recente, declarou que não nega vigência ao art. 9 da Lei de Introdução, a sentença que aplicou a lei portuguesa como lexi loci celebrationis sem reparar numa cláusula contratual em favor do direito inglês ${ }^{(49)}$.

\section{c) O anteprojeto de $1964 / \mathbf{7 0}$}

Ante este panorama, as idéias de Freitas refletem-se unicamente no anteprojeto da Lei Geral de Aplicação das Normas Jurídicas de 1964, revisado em 1970, que admite no seu art. 51 a autonomia da vontade para os contratos, baseando-se expressamente nas regras do Esboço, arts. 32 e 1965 . Porém, o art. 52 do mesmo anteprojeto declara obrigatória a aplicação da lei brasileira aos contratos exequiveis no Brasil, porque «corresponde a uma regra tradicional do direito pátrio, em defesa de nossos interesses, morais, econômicos e sociais, e por isto, aparecida em forma unilateral e imperativa» (50). Assim a influência de Freitas também aqui fica relegada ao segundo plano pela velha tradição do direito brasileiro.

\section{Outros países}

Se no próprio país natal de Freitas as suas idéias não prosperaram não se pode esperar uma maior influência nos países vizinhos.

(45) V. sobre a origem J. SAMTLEBEN, Derecho cit. (supra n. 1), 248, nota 22, e para a interpretação as notas seguintes.

(46) V. autores citados por I. STRENGER, Op. cit., (supra n. 43), 201 ss.

(47) A. DE CARVALHO, Contrato por correspondência com firma estrangeira, in Revista Forense, 155, 1954, 103 ss.; A. WALD, Da validade das convencões sobre foro do contrato $\odot$ da aplicạão da lei estrangeira às convenções celebradas no Brasil, in Revista dos Tribunais, 345, 1964, 58 ss., 64 ss.; L.G.P. DE BARROS LEĀES, Arbitragem comercial internacional, in Revista Forense, 221, 1968, 421 ss.

(48) V. jurisprudência citada por G. GARLAND, Op. cit., (supra n. 42), 54 s.

(49) Supremo Tribunal Federal, Ac. 17.12-1981, Recurso extraordinário no 93.131, «Champalimaud c. Banco do Brasil S/A. e outros», Revista Trimestral de Jurisprudência, 101, 1982, 1149 ss., 1167 s.

(50) H. VAltadão, Lei Geral de Aplicação das Normas Jurídicas, Anteprojeto oficial, Rio de Janeiro, 1964, 25, 90 ss., 93; a versão revisada do Projeto de 1970 encontra-se em H. VALLADãO, Material cit. (supra n. 39), 159 ss., 171. 
Não é possível dar aqui um panorama geral do problema da autonomia da vontade nos países latino-americanos. Por isso limitamo-nos a alguns exemplos para demonstrar como nestes países a concepção territorialista de Bello e Story triunfou sobre a posição voluntarista de Savigny e Freitas.

\section{a) $\mathbf{O}$ grupo chileno}

$\mathrm{Na}$ primeira parte desta conferência já aludimos à norma do art. 16 do Código Civil chileno de 1855 que reflete as idéias de Bello sobre o direito aplicável aos contratos. É a lei do lugar da celebração que rege o contrato, respeitando o direito chileno quando este é a lei do lugar da execução. A jurisprudência entendeu que esta ressalva em favor da lei chilena somente opera de maneira unilateral, e sujeita os contratos celebrados no Chile à lei chilena, mesmo se o lugar da execução se encontre no estrangeiro ${ }^{(51)}$.

$\mathrm{Na}$ doutrina chilena discute-se a possibilidade duma autonomia das partes para determinar a lei do contrato. Para isso os autores baseiam-se na disposição do art. 1545 do Código Civil que considera o contrato como lei entre as partes ${ }^{(52)}$. Também na jurisprudência se encontram alguns julgados que se inclinam neste sentido, especialmente quando as partes elegeram a lei chilena. Porém, na prática, domina a tendência territorialista, aplicando-se o direito chileno mesmo contra uma declaração expressa das partes ${ }^{(53)}$.

A mesma situação encontramos nos países que seguem o modelo do Código Civil chileno. Assim, no Equador uma parte da doutrina reconhece uma certa autonomia das partes baseando-se na aludida norma do Código Civil, enquanto que a Corte Suprema não admite a eleição da lei do contrato pelas partes, quando este se firmou no Equador ${ }^{(54)}$. Igualmente na Colômbia a idéia da autonomia das partes não encontrou apoio na prática ${ }^{(55)}$. Somente na Venezuela, cujo Código Civil se afastou do modelo chileno pelas modificações posteriores, mas mantinha a regra mencionada sobre o contrato como lei entre as partes, a jurisprudência tem admitido expressamente a elei-

(51) Corte Suprema, Sent. 9.12-1930, «Banco de Tacna c. Espada y Donoso Hnos.», Revista de derecho, jurisprudencia $\mathbf{y}$ ciencias sociales, 28, 1931, $2^{q}$ parte, sec. 1, p. 409 ss., 416.

(52) F. ALBONICO VALENZUELA, Manual de derecho internacional privado, II, Santiago de Chile, 1950, 97 ss.; M. RAMfREZ NECOCHEA, Síntesis del derecho internacional privado chileno, I, Santiago de Chile, 1965, 21 ss., 25; E. Hamiltón, Solución de conflictos de leyes $y$ jurisdieción en Chile, Santiago de Chile, 1966, 295 ss.

(53) V. jurisprudéncia citada por A. ETCHEBERRY O., American-Chilean Private International Law, New York, 1960, 58 ss. Sobre a eleição da lei chilena pelas partes $\nabla$. Corte Suprema, Sent. 31.10-1918, «Ramos c. Cía. de Azúcar de Chichlayo», Revista de derecho, jurisprudencia: ciencias sociales, 16, 1919, 2a parte, sec. 1, p. 365 ss., 401 s., 404.

(54) J.I. LARREA HOLGUIN, Manual de derecho internacional privado, Quito, 1962, 212 y 320.

(55) C. BUENO-GUZMAN, EI derecho internacional privado interno en Colombia, in Universitas. Ciencias iurídicas $\mathbf{y}$ socioeconómicas, 51, 1976, 159 ss., 189 s. ; PH. J. EDER, American-Colombian Private International Law, New York, 1956, 57 ss. 
ção da lei do contrato, sendo esta nos casos citados a lei venezuelana ${ }^{(56)}$. E o projeto venezuelano de 1965 reconhece abertamente a autonomia das partes no sentido moderno, relembrando assim as idéias que Teixeira de Freitas desenvolveu no Brasil precisamente cem anos antes no seu Esboço ${ }^{(57)}$.

\section{b) Argentina}

Consideração especial merece o Código Civil argentino de 1869 que se elaborou pela maior parte justamente em base do Esboço de Teixeira de Freitas ${ }^{(58)}$. O autor do Código Civil, Dalmacio Vélez Sarsfield, que estava em contato direto com o seu grande contemporâneo brasileiro, deixava tambëm inspirar-se, na matéria do direito internacional privado, pelas idéias de Joseph Story. O resultado é uma mistura de concepções divergentes que causa para a doutrina argentina problemas árduos de interpretação ${ }^{(59)}$. Assim, na parte sobre os contratos, Vélez Sarsfield copiou nos arts. 1209-1216 quase literaImente os arts. 1962 e ss. do Esboço de Freitas. Porém, os precedentes arts. 1205-1208 do Código Civil correspondem exatamente às passagens respectivas do livro de Joseph Story (60).

Seguindo o pensamento de Story, o art. 1205 sujeita os contratos feitos fora do território argentino às leis do lugar da celebração. Porém, para os contratos celebrados no território argentino ou fora dele para ter sua execução na Argentina, ou celebrados na Argentina para serem executados fora dela, os arts. 1209 e 1210 declaram aplicável a lei do lugar da execução, seguindo o modelo do art. 1962 do Esboģo. Para conciliar estas disposições, a doutrina argentina inventou construções complicadas, limitando o âmbito do art. 1205 aos contratos sem pontos de conexão com o território argentino. Porém, outros autores consideram sempre aplicável a lei do lugar da execução do contrato, se este não coincide com o lugar da celebração, unindo assim o pensamento de Story com as idéias de Freitas ${ }^{(61)}$.

No entanto, Vélez Sarsfield no seu Código Civil não copiou os arts. 32 e 1965 do Esbboço sobre a eleição da lei do contrato pelas partes. Como ele seguiu quase literalmente todas as demais regras

(56) V. jurisprudência citada por J. SAMTLEBEN, La aplicación del Código Bustamante en Venezuela, in Libro Homenaje a la memoria de Joaquín Sánchez-Covisa, Caracas, 1975, 319 ss., 337.

(57) Exposición de motivos y proyecto de ley de normas de derecho internacional privado, Caracas, 1965, p.8, 17, arts. $29,31 \mathrm{~s}$.

(58) S. MEIRA, Op. cit. (supra n. 40), 292 ss., 305 ss.; IDEM, Direito brasileiro e direito argentino, Códigos comercial o civil: Influência do «Esboce» de Teixeira de Freitas ao Projeto de Vélez Sarsfield, in Studi Sassaresi, III, v. 5, 1977-78 (1981), 201 sS., 228 ss.

(59) V. sobre isso J. SAMTLEBEN, Der Territorialitätsgrundsatz im Internationalen Privatrecht Lateinamerikas, in Rabels Zeitschrift für ausländisches und internationales Privatrechet3, 35, 1971, 72 ss., 97 s.

(60) H. VALLADAO, The Influence cit. (supra $n \mid 6$ ), $37 \mathrm{~s}$.

(61) V. sobre as diferentes opiniões H. GRIGERA NAÓN, Les contrats internationaux en Argentine, in Droit et pratique du commerce international, 7, 1981, 427, 428 s. 
do Esboço sobre os contratos, esta omissão parece ser o resultado duma decisão consciente contra a autonomia das partes, influenciada pelo pensamento de Joseph Story. Não faltam na Argentina as tentativas de reconhecer esta autonomia no direito internacional privado, baseando-se na norma do art. 1197 do Código Civil, que considera os contratos, lei entre as partes ${ }^{(62)}$, ou no direito consuetudinário ${ }^{(63)}$. Porém, a doutrina tradicional nega-se a reconhecer a autonomia das partes como direito vigente e a conceder aos arts. 1205 e ss. mero valor subsidiário (64). Conseqüentemente, segundo estas normas as partes no direito internacional privado argentino somente dispõem duma autonomia indireta através da escolha do lugar de execução ${ }^{(65)}$.

\section{Os tratados}

Para finalizar este estudo, vamos dar um breve resumo dos tratados latino-americanos no âmbito do direito internacional privado e das soluções que eles brindam para os problemas dos contratos internacionais. Sem deter-nos com os vários tratados do século XIX que contêm cláusulas expressas sobre este assunto ${ }^{(66)}$, limitamo-nos aqui aos grandes tratados multilaterais hoje em vigor, que são os Tratados de Montevidéu e o Código Bustamante, e aos trabalhos atuais da Organização dos Estados Americanos.

\section{a) Os Tratados de Montevidéu}

Os Tratados de Montevidéu de 1889, que foram ratificados pela Argentina, Bolívia, Paraguai, Peru, Uruguai e depois Colômbia, baseiam-se no pensamento de Story e Savigny e também no Código

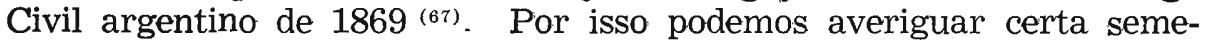

(62) M. ARgúas - C.A. LAZCANO, Tratado de Derecho Internacional Privado, Buenos Aires, 1926, 274 ss.; B. KALLER DE ORCHANSKY, Régimen de los contratos en derecho internacional privado argentino, in Revista Española de Derecho Internacional, 19, 1966, 519 ss., 524,529 s.

(63) W. GOLDSCHMIDT, Derecho Internacional Privado 4, Buenos Aires, 1982, 191 ss., 198 ss., 393; A. BOGGIANO, Derecho Internacional Privado, Buenos Aires, 1978, 458 ss.; IDEM, International Contracts in Argentina, in Rabels Zeitschrift für ausländisches internationales Privatrecht, 47, 1983, 431, 433 s., 459 ss., referindo-se à prática do Estado argentino de aceitar nos contratos internacionais de empréstimo cláusulas sobre eleição do foro e da lei aplicável. V., porém, sobre a recente decisão dum juiz de Rio Gallegos contra esta prática, J. SAMTLEBEN, «Der Kampf ums Forum»: Ein Gefecht in Patagonien, in Rabels Zeitschrift, ibidem, p. 738 ss.

(64) V. a resolucão das «Sextas Jornadas de Derecho Civil» de 1977, citada por M.A. CIURO CALDANI, Algunas consideraciones acerca de las vi Jornadas de Derecho Civil y el derecho internacional privado, in La Ley, 1978, B, 820 ss.; criticamente W. GOLDSCHMIDT, El derecho internacional privado en las Sextas Jornadas de Derecho Civil, in El Derecho, 75, 1978, 781 ss., 783.

(65) H. GRIGERA NAON, Op. cit. (supra n. 61), 429, 432 s.

(66) V. sobre estes tratados J. SAMTLEBEN, Derecho cit. (supra n. 1), 7 ss., notas 28 y 94.

(67) V. ibidem, p. 15 ss., 284 ss., 293 s. 
lhança com as idéias de Teixeira de Freitas, as quais por esta via indireta influenciaram especialmente as regras do Tratado de Direito Civil Internacional de 1889. Assim, na matéria dos contratos internacionais, os arts. 32 e 33 declaram aplicável a lei do lugar da execução do contrato. Seguindo o modelo do Código Civil argentino inspirado por Freitas - e contrariando o pensamento de Savigny este lugar de execução é considerado como centro do contrato inteiro, evitando assim a divisão nas várias obrigações contratuais. Esta concepção unitária do Tratado, que contém regras especiais para a determinação desse lugar nos seus arts. 34 e ss., é também confirmado pela jurisprudência (68).

Porém, o Tratado de Montevidéu de 1889, como já o Código Civil argentino, afasta-se do pensamento de Freitas, não admitindo a autonomia da vontade das partes na determinação da lei do contrato (69). Isto resulta do caráter obrigatório das suas normas e é confirmado pela doutrina ${ }^{(70)}$ e jurisprudência ${ }^{(71)}$. Na revisão dos Tratados de Montevidéu em 1939/40, esta questão foi discutida, mas resolvida em sentido negativo (72). Assim o Protocolo Adicional aos Tratados de 1940, vigente entre Argentina, Paraguai e Uruguai, declara no seu art. 5 expressamente:

«La jurisdicción y la ley aplicable según los respectivos Tratados, no pueden ser modificadas por voluntad de las partes, salvo en la medida en que lo autorice dicha ley.»

Esta norma, que depois foi copiado no art. 2403 do Código Civil do Uruguai, exclui terminantemente a livre eleição da lei aplicável pelas partes, somente reconhecendo a autonomia substantiva das partes no âmbito do direito dispositivo (73).

\section{b) O Código Bustamante}

O Código Bustamante, votado pela Sexta Conferência Internacional Americana de Havana, em 1928, está vigente entre quinze nações

(68) Juzgado Comercial de la Capital, Sent. 29.4-1964, «Banco de Montevideo c. Cia Azucarera Tucumana», Jurisprudencia Argentina, 1964, VI, 240 ss., 244: «La determinación de una ley única ... es lógica si se advierte que se debe aplicar para un solo contrato una sola regulación legal para evitar distinción de trato entre las partes en igualdad de situaciones, en una misma relación».

(69) Cf. Actas de las sesiones del Congreso Sud-Americano de derecho internacional privado, Buenos Aires, 1894, 492 ss.

(70) W. GOLDSCHMIDT, Derecho cit. (supra n. 63), 197, 392; Q. ALFONSIN, Régimen internacional de los contratos, Montevideo, 1950, $31 \mathrm{~s}$.

(71) Cf. Supremo Corte de Justicia Nacional, Sent. 28.9-1931, «Molins y Cía. c. Ferrocarril Central de Buenos Aires», Jurisprudencia Argentina, 36, 1931, 839, em relação ao Tratado de Direito Comercial Internacional de 1889.

(72) J.L. BUSTAMANTE I RIVERO, El Tratado de Derecho Civil Internacional de 1940, Montevideo, 1942, 109 s., 165 ss.

(73) Esta concepção do Tratado é contrariado por W. GOLDSCHMIDT, Derecho cit. (supra n. 63), 392, que admite a livre eleição da lei aplicável através dum renvoi do direito naclonal. 
latino-americanas, sendo aplicado também em relação a Estados não-contratantes ${ }^{(7+)}$. O seu autor, o jurisconsulto cubano Antonio Sánchez de Bustamante y Sirvén, estava influenciado pela doutrina manciniana da Escola Italiana do século XIX. Reconhecendo a liberdade das partes, à qual ele chamava «autarquía personal», admitiu a eleição da lei do contrato, embora a restringisse ao âmbito do direito dispositivo segundo os conceitos da lex fori (75). No Código Bustamante, essa sua opinião encontrou expressão defeituosa no art. 166:

«As obrigações que nascem dos contratos têm força de lei entre as partes contratantes e devem cumprir-se segundo o teor dos mesmos, salvo as limitações estabelecidas neste Código.»

Esta norma, que corresponde ao art. 1091 do Código Civil espanhol e cubano, e que se encontra na mesma forma em quase todos os Códigos latino-americanos, não teve muita influência no direito internacional privado dos Estados contratantes. Foi considerado como uma regra de direito substantivo e como tal aplicada na jurisprudência brasileira ${ }^{(76)}$. Somente nos Estados onde já a respectiva norma do Código Civil fora discutida no direito internacional privado, também o art. 166 do Código Bustamante foi mencionado neste contexto. Assim uma sentença chilena se baseou nele para convalidar uma cláusula contratual em favor do direito norte-americano, mas foi anulada por via de apelação (77). Na jurisprudência venezuelana, porém, o art. 166 foi citado para justificar a aplicação do direito venezuelano que as partes tinham escolhido no seu contrato, sendo este argumento reprovado na instância superior (78).

\section{c) Os trabalhos da OEA}

A Organização dos Estados Americanos (OEA) desde a sua fundação tem-se ocupado com «o desenvolvimento e a codificação do direito internacional privado». A Carta da OEA de 1948 previa no seu art. 67 que o Conselho Interamericano de Jurisconsultos trataria do assunto. A comissão permanente deste Conselho, o Comitê Jurídico Interamericano, publicou no ano de 1966 um projeto de reforma do Código Bustamante, combinando este com as regras dos Tratados de Montevidéu. Na matéria dos contratos, o projeto abandona o critério do Código Bustamante e segue as conexões objetivas dos Tra-

(74) J. SAMTLEBEN, Derecho cit. (supra n. 1), 64 ss., 177 ss.

(75) Tbidem, 223 ss.

(76) Juizo da 4* Vara Civel do Districto Federal, Sent. 21-111931, «Biolchini c. Caldeira Brant», Archivo Judiciário, 21, 1932, 80 (91) - Revista Forense, 58, 1932, 324 (334), sobre a validade duma cláusula valor-ouro.

(77) Corte del Trabajo, Sent. 29.3-1962, embargos de terceiro nos autos «Caja de Empleados Particulares c. Sociedad de Transportes Aéreos ALA», Revista de derecho, jurisprudencia $\mathbf{y}$ ciencias sociales, 59, 1962, 2* parte, sec. 1, p.261.

(78) V. as decisões citadas por J. SAMTLEBEN, La aplicación cit. (supra n. 56), 337. 
tados de Montevidéu, sem dar margem à autonomia da vontade das partes ${ }^{(79)}$.

Estes trabalhos de reforma encontraram sua continuação nas Conferências Especializadas Interamericanas sobre Direito Internacional Privado. Porém, as primeiras conferências do Panamá em 1975 e de Montevidéu em 1979 não trataram da lei aplicável aos contratos internacionais ${ }^{(80)}$. Este assunto tampouco aparece na agenda da Terceira Conferência Especializada, prevista para 1984. Entretanto, na Europa a Convenção de Roma de 1980 empreendeu a unificação do direito internacional privado dos contratos no âmbito das Comunidades Européias. '́ de esperar que nas futuras Conferências Interamericanas esta matéria também encontre seu tratamento apropriado. Para isso não é preciso seguir o modelo europeu. Antes, uma futura convenção interamericana pôde basear-se na própria tradição do continente, relembrando os ensinamentos do grande jurista brasileiro Augusto Teixeira de Freitas.

(79) Proyecto de Código de Derecho Internacional Privado, in Trabajos realizados por el Comité Jurídico Interamericano durante su Período Ordinario de Sesiones (Julio-Octubre de 1966), Unión Panamericana, Washington D.C., 1966, p.16 ss., 38, arts. 122 ss.

(80) V. sobre estas conferências J. SAMTLEBEN, Derecho cit. (supra n. 1), 41 ss., e os estudos alì citados; IDEM, Die Interamerikanischen Spezialkonferenzen für Internationales Privatrecht, in Rabels Zeitschrift für ausländisches und internationales Privatrecht, 44, 